\title{
Prevalence and Risk Factors of Domestic Violence among Mongolian Women
}

\author{
Shagdarsuren Oyunbileg, M.D., MAHMPP, Nyamjav Sumberzul, M.D., Ph.D., ${ }^{2}$ \\ Natsag Udval, M.D., ScD(Med), Jung-Der Wang, M.D., Sc.D., ${ }^{1,4}$ and Craig R. Janes, Ph.D. ${ }^{5}$
}

\begin{abstract}
Aims: The purpose of this study was to investigate the prevalence and determinants of domestic violence in Mongolian women.

Methods: The survey was administered to 5500 people in 1000 households randomly selected from two districts of Ulaanbaatar, Mongolia.

Results: The response rate was $90.3 \%$ (total of 4967 , and 3338 were women.). About $37.7 \%$ of respondents reported that they were affected by some type of domestic violence during the previous 6 months; $17.9 \%$ of all respondents reported physical violence, $21.9 \%$ reported emotional violence, $10 \%$ reported sexual abuse, and $6.9 \%$ reported financial violence. Major risk factors for violence against women included having only a primary education or less, low income, living in a rented house, and living with an unemployed partner who uses alcohol.

Conclusions: Domestic or intimate partner violence (IPV) is widespread in Mongolia and is usually committed in family circles, often away from public view. This study suggests that increasing employment for men may help reduce poverty and alcohol abuse and, thus, IPV.
\end{abstract}

\section{Introduction}

D OMESTIC VIOLENCE IS DEFINED as a pattern of violent or coercive behavior that one family member uses against other family members. It is a gendered and morally sensitive problem that violates human rights and incurs substantial social, economic, and health costs. ${ }^{1}$ Violence is considered to be a paramount issue of public health concern by the World Health Organization (WHO) and the United Nations (UN). In the world, nearly $95 \%-98 \%$ of the victims of domestic violence are female, and 4-6 million women a year are battered. ${ }^{2}$ Five percent of health disorders affecting women of childbearing age and $6 \%$ of female deaths are caused by domestic violence in Shanghai city of China, and 1 in every 4 married women in the United States has been assaulted by her spouse. ${ }^{3}$

Mongolian society has a tradition of protecting women from violence. In the 13th century, Mongolia developed a legal code that severely punished offenders who abused women, who caused pregnant women to miscarry, or who touched personal belongings of women without permission. ${ }^{4}$
Mongolia acceeded in 1981 in the Convention of the United Nations on the Elimination of All Forms of Violence of Discrimination against Women, ${ }^{5}$ and Mongolian citizens' lives and security are guaranteed in the Mongolian Constitution. The Government Policy on Public Health, which was formally adopted in 2002, states that it is a requirement of government to "establish a favorable psychological environment for families, communities, and society as well as preventing and combating violence." ${ }^{\prime 6}$ In 2003, the Mongolian Parliament endorsed the State Policy on Family Development, which proposed a motion to advance legislative regulation on combating violation of the human rights of family members, including neglect and abuse. ${ }^{7}$ In addition, both the Mongolian National Program on Reproductive Health, 2002, and Mental Health Program, 2002, highlight the central values of human rights and gender equity and encourage the development of a violence-free environment. $^{8-10}$

Despite the existence of such formal policy-level statements, however, preliminary studies ${ }^{11}$ conducted by local nongovernmental organizations (NGOs) found that a quarter

\footnotetext{
${ }^{1}$ Institute of Occupational Medicine and Industrial Hygiene, College of Public Health, National Taiwan University, Taipei, Taiwan.

${ }^{2}$ School of Public Health, Health Science University of Mongolia, Ulaanbaatar, Mongolia.

${ }^{3}$ Academy of Health Management, Ulaanbaatar, Mongolia.

${ }^{4}$ Department of Environmental and Occupational Medicine, National Taiwan University Hospital, Taipei, Taiwan.

${ }^{5}$ Faculty of Health Sciences of Simon Fraser University, Burnaby, Canada.
} 
of the victims of violence were abused physically, two thirds were abused psychologically, and one tenth suffered from economic or financial restrictions or violence due to alcoholism, suspicion, and quarrels within the family. Divorce and violence against children as a result of alcoholism and hidden violence are reported to be common. Although there have been relatively few studies of the specific risk factors predicting intimate partner violence (IPV), poor living conditions and poverty are reported by organizations as being the main reasons for beating of children and quarrels between marriage partners. ${ }^{12}$ These occurrences seem to be on the rise in the Mongolian family, although such reports are largely anecdotal.

Family, rather than the individual person, has been the basic unit of social group in Mongolia, and traditionally, most lived in nuclear families composed of a married couple, their children, and perhaps a widowed parent. The number of extended families has increased in the past three decades. The Population Census-2000 showed $19.9 \%$ of families with 6-8 members and $9.5 \%$ with $\geq 8 .{ }^{13}$ Urban families were generally larger than rural families. Most herder (or rural) families and about half of capital city residents have lived in a traditional Mongolian tent or ger or yurt, which makes all members physically and psychologically close to each other. Each married couple occupied its own tent, and sons usually received their share of the family herd at the time of their marriage. The usual pattern was for one son, often the least resourceful son, to inherit the headship of the parental herd and tent, whereas daughters married out to other families. Women of extended families traditionally share day-to-day tasks of child care and household chores and also share similar values and attitudes in life. Mongolian women have legal equality, but once in the labor force, they often were doubly burdened with both housework and child care in addition to a day's work for wages.

The country has been facing numerous challenges because of its economic and political transition since the previously conducted surveys. The social crisis accompanying transition to a market economy has hit women harder than men, and the proportion of unemployed women is consistently higher than that of men. In 2002, female-headed households numbered more than 55,000, one in four of these families have six or more children, and about half of the female-headed households are poor. ${ }^{14}$ Many more households function in practice as female-headed households where the men are unemployed or are unable to work because of ill health or alcoholism.

Therefore, there is a need to design and conduct a study to understand the magnitude of and risk factors for this problem and to provide evidence for the development of national policy on the prevention of IPV. We conducted this survey to determine the prevalence of and risk factors for domestic violence in Mongolia.

\section{Materials and Methods}

\section{Study design}

The survey was conducted from January 20 to April 1, 2004, in the Bayanzurkh and Songinokhairkhan districts of Ulaanbaatar. We applied a cross-sectional, population-based household survey design for the conduct of this study. The study was approved by the ethical committee of the Ministry of Health of Mongolia before commencement.
According to the Mongolian population census of $2000,{ }^{13}$ $31 \%(760,000)$ of the total Mongolian population live in the capital city Ulaanbaatar, which is divided into nine districts. Because a winter disaster during 2002-2003 destroyed the livelihoods of rural herders, two districts (Songonikhairkhan and Bayanzurkh) have experienced a major influx of migrants from outside of Ulaanbaatar. These migrants tend to experience high levels of unemployment and subsistence insecurity. Thus, the two districts were composed of both people from the traditional urban community and rural migrants and were considered suitable for studying the issue of IPV. Nearly $20.3 \%$ of the population of Ulaanbaatar lived in the Songinokhairkhan district, $19.4 \%$ lived in the Bayanzurkh district; $19.8 \%$ of the unemployed population lived in Bayanzurkh, and $23 \%$ lived in the Songinokhairkhan district. We drew a sample of these districts based on random numbers generated from the Census registry, which comprised $1 \%$ of the total population of Ulaanbaatar, in order to increase the representativeness of the age strata. Households were selected until the predesigned sample size, 5500, was achieved.

\section{Settings and participants}

After establishing the lists of sampled households, we sent four teams of five members to collect data in the 50 households of each village (khoroo in Mongolian) near the two district centers and two teams of three members to the remote villages.

Face-to-face interviews were conducted within households, and those aged $>15$ years were invited for an interview; a random number chart was used to select the women to interview. The study team visited respondents' homes on weekends to increase the likelihood of reaching all working women. To ensure the accuracy of information from the interviews, all interviewers were trained together and taught standardized techniques for using the tools during a day seminar. All interviewers had good communication skills, were empathic and supportive, and had previous field research. Although there were often several members interviewed in the same household, all interviews were conducted individually and separately in a private place to insure the confidentiality of respondents. Women were interviewed only by women researchers. We present the study findings about violence against women in this article and will summarize data about violence against men elsewhere.

\section{Outcome measures}

The study questionnaire was developed by the core research team, which included representatives from different health and social welfare research organizations, National Center against Violence, Human right Centre, and other women's NGOs. The questionnaire comprised four parts: part 1 inquired about the demographics, family characteristics, and socioeconomic status (SES) of the respondents and intimate partners; part 2 collected data about respondents' attitudes toward violence; part 3 described their violence experiences and the nature of the violence; part 4 included health consequences from the violence. All interviews were conducted in the Mongolian language. A pretest of the questionnaire was conducted, and necessary modifications were made before this survey. All questionnaires were coded 
anonymously according to the requirement of safety protocol to protect confidentality.

We have adopted the following definitions of violence from the $\mathrm{WHO}^{15,16}$; physical violence is defined as the use of physical force against another person or group that results in physical, sexual, or psychological harm. It includes, among others, beating, kicking, hitting, pushing, slapping, pinching, and injuring. Emotional abuse is defined as the intentional use of power, including threat of physical force, against another person or group by ignoring, rejecting, insulting, yelling, bullying/mobbing, swearing, intimidation, disheartening, isolating, and restricting normal contact with others. We have included an open-ended question in part 3: In the last 6 months, has your partner ever caused psychological harm or a dispute with you? If yes, could you specify or list it? How often has such behavior occurred?

In addition, this study explored the abuse that is imposed through financial control, namely, threats of no financial support, withholding money, financial restrictions on spending, and extortion and control of one's money by another.

\section{Statistical analysis}

In addition to the summary statistics of frequency distributions, we conducted multiple logistic regression to estimate odds ratios (ORs) and 95\% confidence intervals (CIs) for identified risk factors. Statistical analysis was performed using SPSS for Windows, release 11.0 (SPSS, Chicago, IL).

\section{Results}

A total of 5500 subjects were originally invited to be interviewed in the 1100 households. Among them, 438 refused to participate, 63 provided only demographic information, and 32 did not finish the questionnaire. Thus, a total of 4967 subjects in the households completed the survey questionnaire, with an overall response rate of $90.3 \%$; 3338 of the respondents were women, with a response rate of $92.4 \%$. A summary of the demographic characteristics of respondents is provided in Table 1.

Of the respondents, $43 \%$ resided in the Bayanzurkh district and $57.4 \%$ resided in the Songinohairkhan district. About $53.1 \%$ of women reported being legally married. Nearly $7 \%$ of women were living with men without official marriage, $8.2 \%$ were divorced, 3.3\% were widowed, and the remaining $32.1 \%$ respondents had never married. The average family size was $5 \pm 2$, and $>68.5 \%$ of the respondents had a household size of between 3 and 5 , and $18.6 \%$ of families had $>6$ persons. The average number of children under age 5 was $1.3 \pm 1$, and one fourth of families had children $<5$ years old. About one half of families had 2 or 3 children between 6 and 18 years old, and $2.4 \%$ of families had $>4$ children.

About half of interviewed women and about $60 \%$ of their partners had received more than a secondary education, and about $55 \%$ of all were unemployed. Compared with the general population in Mongolia, the respondents were less educated and slightly less employed (Table 1). The average household monthly income was 58,000 $\pm 15,000$ tugrugs (about US\$48 \pm 12 ), about half of the respondents reported $<120,000$ tugrugs (about US\$100), and about a quarter reported earning $>240,000$ tugrugs (about US\$200) per month; $>60 \%$ of this reported income came from a salary. Approxi- mately $11.3 \%$ of respondents' monthly income was below the minimum level of living standards. The minimum standard of living was 26,500-30,000 tugrugs in Ulaanbaatar city. ${ }^{17}$ About $7.9 \%$ of households having $\geq 8$ family members earned $<120,000$ tugrugs a month. Forty-nine percent of the husbands or male intimate partners were still the head of the household for making financial decisions, and only $21.7 \%$ of respondents said they and their partners made the decisions together. About $70 \%$ of respondents were living in a privately owned apartment or ger, and one sixth of respondents had housing problems and were living with relatives or in-laws.

Fifty-two percent $(n=1603)$ of all female respondents were affected by some type of violence during the last 6 months. About $32 \%$ of respondents reported experiencing combined physical, emotional, sexual, or financial violence. Among them, $6.9 \%$ suffered from physical, emotional, and financial abuse together, $36.4 \%$ suffered from physical and emotional abuse, 5\% suffered from physical and sexual abuse, $26.6 \%$ suffered from emotional and financial violence, and $21.9 \%$ suffered from physical and financial violence. The prevalence rates were standardized to the distribution of the Mongolian national population. So weighted, we found that $17.9 \%$ $(n=576)$ were physically battered and $21.2 \%(n=572)$ suffered from emotional abuse. About $7 \%(n=110)$ of respondents reported being threatened by withdrawal of financial support, or what we define here as financial violence. Nearly $10 \%(n=53)$ of respondents suffered from sexual abuse with unwanted sexual advances or sexual harassment, including demanding sex in return for favors; most of these cases occurred among less educated, alcoholic intimate partners. Taking the household as the unit of analysis, 38\% of the responding families experienced some type of violence. As summarized in Table 1, prevalence rates for all forms of violence were higher among females, those 25-44 years of age, those reporting the presence of partners with alcohol-related problems or who were unemployed, and those with lower household incomes.

Almost two thirds $(61.7 \%)$ of the perpetrators of violence were reported to be married partners or expartners or cohabiting unmarried male partners. Other commonly mentioned perpetrators of physical, emotional, and financial abuse were nonpartners $>15$ years old, which included stepparents and stepbrothers or stepsisters $(15 \%-20 \%)$. About $6 \%-14.3 \%$ were parents, parents-in-law, and other male or female family members (Fig. 1). Violence was reported to occur mostly in the home $(84.9 \%)$. Slightly over one third $(35.1 \%)$ of the victims of violence were abused one to three times during the past 6 months, one fifth $(21.2 \%)$ reported a monthly frequency of abuse, one fourth $(26.8 \%)$ reported weekly abuse, and one sixth (16.9) reported nearly daily abuse. Nearly $14 \%$ of violence victims did not contact anybody when they were affected by domestic violence, feeling such contact to be ineffective and to cause suffering to parents and relatives, or they did not know whom they should approach. Thus, most victims prefer to carry the burden of their hardship by themselves.

About $13.2 \%$ of violence victims lost their capacity to work; among them, $30 \%$ were members of families with incomes that were lower than the standard minimum level, which usually created financial difficulty within the family and increased the risk of repeated violence. One quarter of violence victims were forced to leave their jobs because of physical 
Table 1. Frequency Distributions (\%) of Demographic Characteristics of Respondents and Types of Domestic Violence in Surveyed Women, Stratified by Characteristics

\begin{tabular}{|c|c|c|c|c|c|c|c|}
\hline $\begin{array}{l}\text { Characteristics of } \\
\text { women respondents }\end{array}$ & $\begin{array}{c}\text { General } \\
\text { Mongolian }^{\text {Momen }} \\
\text { women }^{\mathrm{a}} \\
(\mathrm{n}=1,276,400)\end{array}$ & $\begin{array}{l}\text { Respondents } \\
(\mathrm{n}=3338)\end{array}$ & $\begin{array}{c}\% \text { of } \\
\text { affected } \\
(\mathrm{n}=1603)\end{array}$ & $\begin{array}{c}\text { Physical } \\
(\mathrm{n}=576) \\
\mathrm{n}(\%)\end{array}$ & $\begin{array}{c}\text { Emotional } \\
(\mathrm{n}=572) \\
\mathrm{n}(\%)\end{array}$ & $\begin{array}{c}\text { Financial } \\
(\mathrm{n}=226) \\
\mathrm{n}(\%)\end{array}$ & $\begin{array}{c}\text { Sexual } \\
(\mathrm{n}=53) \\
\mathrm{n}(\%)\end{array}$ \\
\hline \multicolumn{8}{|l|}{ Age group } \\
\hline $15-24$ & $31.0 \%$ & $845(25.3)$ & 22.4 & $123(14.5)$ & $104(12.3)$ & $42(5.0)$ & - \\
\hline $25-34$ & $26.4 \%$ & $955(28.6)$ & 27.1 & $160(16.8)$ & $166(17.6)$ & $79(8.3)$ & $5(0.5)$ \\
\hline $35-44$ & $21.7 \%$ & $881(26.4)$ & 31.1 & $197(22.4)$ & $173(19.6)$ & $21(2.4)$ & $17(1.9)$ \\
\hline $45-54$ & $10.2 \%$ & $444(13.3)$ & 11.9 & $71(16.1)$ & $74(16.6)$ & $26(5.9)$ & $28(6.5)$ \\
\hline $55-64$ & $5.8 \%$ & $130(3.9)$ & 3.9 & $13(9.7)$ & $30(22.8)$ & $26(20.1)$ & $3(2.3)$ \\
\hline$>65$ & $4.9 \%$ & $83(2.5)$ & 3.6 & $12(14.5)$ & $25(29.5)$ & $32(37.9)$ & - \\
\hline \multicolumn{8}{|l|}{ Women's education } \\
\hline Less than primary/primary & $29.8 \%$ & $1696(50.8)$ & 50.4 & $301(17.7)$ & $286(16.9)$ & $84(5.0)$ & $27(1.6)$ \\
\hline Secondary & $48.1 \%$ & $891(26.7)$ & 25.4 & $144(16.2)$ & $146(16.4)$ & $47(5.3)$ & $15(1.7)$ \\
\hline College/university & $22.1 \%$ & $751(22.5)$ & 24.2 & $131(17.5)$ & $140(18.6)$ & $95(12.6)$ & $11(1.5)$ \\
\hline \multicolumn{8}{|l|}{ Partners' education } \\
\hline Less than primary/primary & $30.7 \%$ & $1278(38.3)$ & 38.8 & $217(16.9)$ & $233(18.3)$ & $63(4.9)$ & $35(2.7)$ \\
\hline Secondary & $50.9 \%$ & $828(24.8)$ & 25.1 & $155(18.7)$ & $148(17.9)$ & $47(5.7)$ & $12(1.4)$ \\
\hline College/university & $18.4 \%$ & $1232(36.9)$ & 36.1 & $204(16.6)$ & $190(15.4)$ & $116(9.4)$ & $6(0.5)$ \\
\hline \multicolumn{8}{|l|}{ Marital status } \\
\hline Married & $57.1 \%$ b & $1772(53.1)$ & 59.9 & $346(19.5)$ & $349(19.7)$ & $116(6.5)$ & $42(2.4)$ \\
\hline Living with nonofficial marriage & & $221(6.6)$ & 6.5 & 32 (14.6) & $43(19.0)$ & $12(5.3)$ & $3(1.5)$ \\
\hline Divorced/widow & $12.1 \%$ & $274(8.2)$ & 8.4 & $51(18.5)$ & $51(18.8)$ & $40(14.8)$ & $5(1.8)$ \\
\hline Not married & $29.8 \%$ & $1071(32.8)$ & 25.2 & $147(13.8)$ & $129(12.1)$ & $58(5.4)$ & $3(0.3)$ \\
\hline \multicolumn{8}{|l|}{ Employment status of women } \\
\hline Yes & $46.1 \%$ & $1472(44.1)$ & 45.4 & $261(17.7)$ & $279(18.9)$ & $53(3.6)$ & $10(0.7)$ \\
\hline No & $53.9 \%$ & $1866(55.9)$ & 54.6 & $315(16.9)$ & $293(15.7)$ & $173(9.3)$ & $43(2.3)$ \\
\hline \multicolumn{8}{|l|}{ Employment status of partners } \\
\hline Yes & $50.3 \%$ & $1415(42.4)$ & 44.8 & $268(19.0)$ & $259(18.3)$ & $89(6.3)$ & $10(0.7)$ \\
\hline No & $49.7 \%$ & $1923(57.6)$ & 55.2 & $308(16.1)$ & $313(16.3)$ & $137(7.1)$ & $43(2.3)$ \\
\hline \multicolumn{8}{|l|}{ Housing } \\
\hline $\begin{array}{l}\text { In own private ger/ } \\
\text { apartment/house }\end{array}$ & $78.6 \%$ & $2330(69.8)$ & 72.5 & $411(17.7)$ & $424(18.2)$ & $147(6.3)$ & $37(1.6)$ \\
\hline $\begin{array}{l}\text { With parents/parent-in-laws } \\
\text { and children }\end{array}$ & $\mathrm{NA}^{\mathrm{c}}$ & $577(17.3)$ & 15.9 & $93(16.2)$ & $86(15.0)$ & 63() 10.9 & $2(0.4)$ \\
\hline Rented house/a room/ger & NA & $391(11.7)$ & 10.4 & $69(17.7)$ & $52(13.3)$ & $16(4.1)$ & $14(3.6)$ \\
\hline $\begin{array}{l}\text { In care houses provided by } \\
\text { government }\end{array}$ & NA & $40(1.2)$ & 1.2 & $3(5.8)$ & $10(24.3)$ & - & - \\
\hline \multicolumn{8}{|c|}{ Household monthly income (thousand tugrugs) } \\
\hline$<119$ & NA & $1632(48.9)$ & 54.6 & $315(19.3)$ & $320(19.6)$ & $152(9.3)$ & $27(1.7)$ \\
\hline $120-239$ & NA & $795(23.8)$ & 25.1 & $120(15.2)$ & $124(15.6)$ & $48(5.9)$ & $18(2.3)$ \\
\hline$>240$ & NA & $911(27.3)$ & 20.3 & $141(15.4)$ & $128(14.1)$ & $26(2.9)$ & $8(0.9)$ \\
\hline \multicolumn{8}{|l|}{ Partner uses alcohol } \\
\hline Yes & NA & $2096(62.8)$ & 68.7 & $423(20.2)$ & $419(20.0)$ & $152(7.3)$ & $34(1.6)$ \\
\hline No & NA & $1242(37.2)$ & 31.3 & $153(12.3)$ & $153(12.3)$ & $74(5.9)$ & $19(1.5)$ \\
\hline
\end{tabular}

${ }^{\mathrm{a}}$ From Mongolian population census-2000. ${ }^{13}$

bincludes Living with nonofficial marriage.

${ }^{\mathrm{c}} \mathrm{NA}$, not available.

injuries (17.6\%), suspicion of office sexual affairs (27.3\%), being ashamed to see colleagues (20.5\%), and boss's misunderstanding and unhappiness with the situation (10.2\%).

The current Mongolian system requires migrants from rural areas into a city to register for an identification card that entitles employment and health and social insurance, but many had no personal documentation or identification, could not afford the registration fee, or had no permanent residence. Unregistered family members and respondents cohabiting were abused two times more than members from officially registered or permanently settled families.
The results of multiple logistic regression with estimations of ORs for physical, emotional, and financial violence are shown in Table 2. Women, those with low incomes, those living in rented houses, and those staying with an unemployed partner who uses alcohol were major risk factors for physical, emotional, and financial violence. A partner's use of alcohol had the highest OR for physical violence (OR 16.7, 95\% CI 11.4-24.4) and for emotional violence (OR 15.8, 95\%CI 10.9-22.9). Women aged 25-44 were at higher risk for physical violence over those of other age groups. Women $>65$ years old had an increased risk of emotional violence (OR 2.59, 95\% 
CI 1.07-2.11). The most significant risk factors for financial violence were low income (OR 2.01, 95\% CI 1.1-5.9), living in rented houses (OR 2.4, 95\% CI 1.2-3.4), and living with parents or parents-in-law and children (OR 2.5, 95\% CI 1.3-4.9).

\section{Discussion}

This study, to our knowledge, is the first to document the high prevalence of physical, emotional, and financial violence against women in Mongolia. Although the study subjects were sampled only from metropolitan Ulaanbaatar, about $38 \%$ of the Mongolian population now lives in this city, and about $40 \%$ of people in Ulaanbaatar reside in the two districts in which the study was conducted.

Although the proportions of respondents between ages 25 and 55 appeared slightly higher compared with the general population of Mongolia, they were largely similar in age distribution (Table 1). Given the large sample size and the high response rate, we believe that the study is reasonably representative. However, as about half of the women in this study had a primary education only, our results cannot be directly generalized to women with higher education. Our results show that the prevalence rates of physical violence $(17.9 \%)$ among Mongolians are somewhat less than those found in other studies of community or national surveys. The WHO Multi-country Study $^{18}$ reported higher prevalence rates of physical violence for Thailand (23\%), Brazil (27\%), Bangladesh $(40 \%)$, and Peru (49\%). Rates of sexual violence in this study $(10 \%)$ were also lower than those reported in Bangladesh (37\%), Thailand $(30 \%)$, and Peru $(23 \%) .{ }^{18}$ Rates of emotional violence in our study $(21.9 \%)$, however, were found to be similar to those reported for some other Asian and Latin American countries, ${ }^{18}$ Israel (24\%), and Australia (22\%).
Such differences might be related to the different research designs, as well as to variability in the definition and operationalization of violence. The most frequently mentioned emotional abuses were insults, ignoring and belittling, and intimidation, which were similar to findings of the WHO study. ${ }^{18}$

Mongolian women may be less comfortable in sharing private experiences of suffering compared with women from western countries. In the traditional nomadic and seminomadic lifestyle, women have limited numbers of friends and colleagues in the small community. Thus, in general, most Mongolian women respect the authority of husbands or intimate partners and hope to resolve disputes within the family by themselves. They would not easily tell outsiders shameful things that happened within their families for fear of losing respect or experiencing further violence. As several Mongolian proverbs used for teaching of children say: A broken or cracked bone is better than lost honor or reputation; Always smile in front of people and do not show people your weakness; Sausage may be broken while cooked, but it is still in our pot. Moreover, some women were afraid that outsiders might not believe their stories or that telling others would not help. Because of the hidden nature of physical, emotional, and financial abuse and the stigma attached to such abuses, current figures may be an underestimation of the true magnitude of IPV in Mongolia.

Consistent with many other studies, multiple logistic regression analyses showed that risk of IPV was associated with older age, being married, unemployment, lower income, and alcohol use. ${ }^{19-24}$ After adjusting for all risk factors, low level of educational attainment was associated with physical violence only. In addition, we also found that there was a significant association between emotional violence and being divorced, which has also been reported by Neff et al. ${ }^{25}$

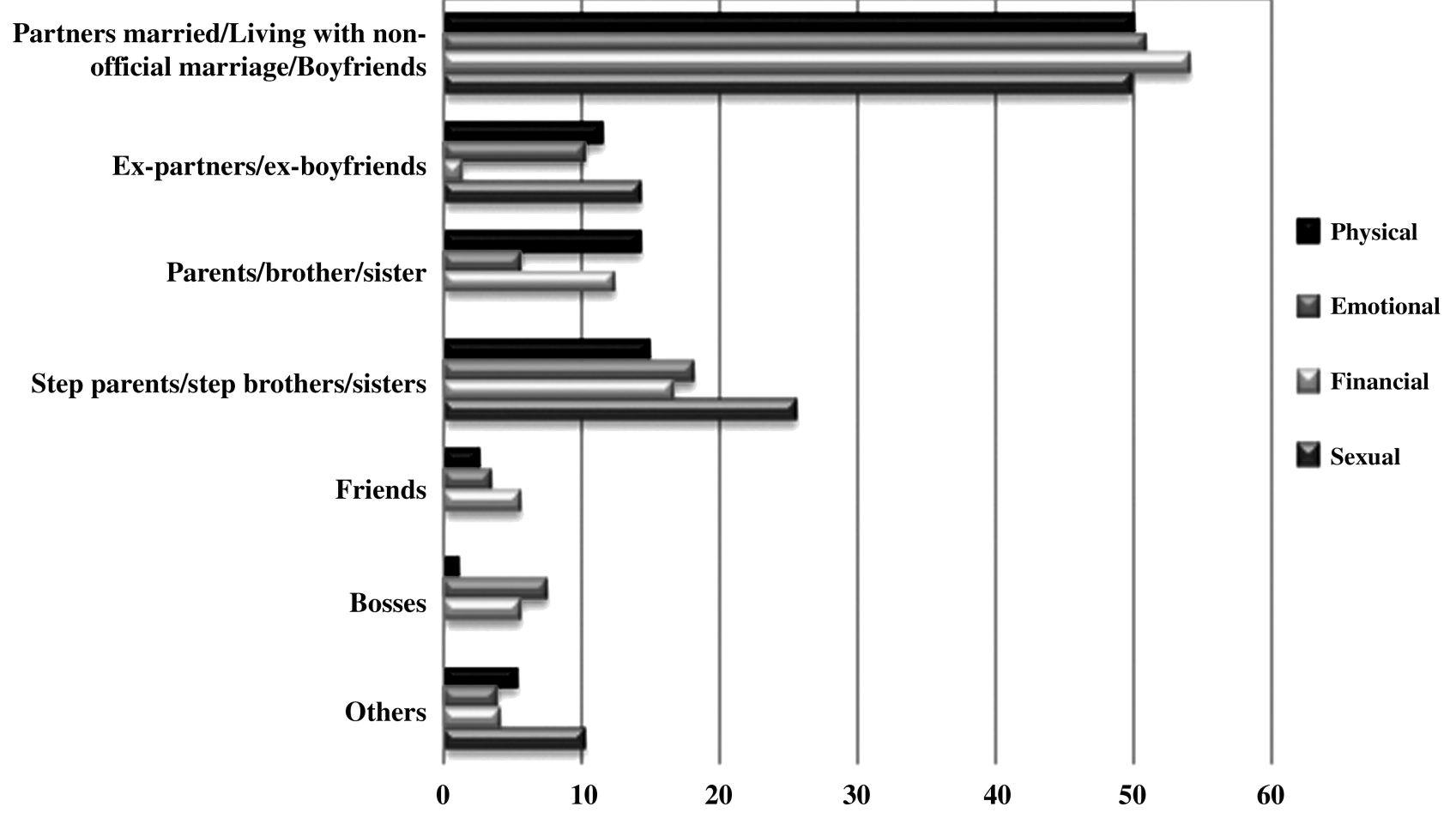

FIG. 1. Frequency distributions (\%) of types of domestic violence in surveyed women, stratified by type of perpetrators. 
Table 2. Estimates of Odds Ratios and 95\% CI (Confidence Intervals) for Different Kinds of Domestic Violence Derived from Multiple Logistic Regression Based on the Survey of 3338 Women in UlaanbaAtar

\begin{tabular}{|c|c|c|c|}
\hline Characteristics of violence victims & Physical $(\mathrm{n}=576)$ & Emotional $(\mathrm{n}=572)$ & Financial $(\mathrm{n}=226)$ \\
\hline \multicolumn{4}{|l|}{ Age group } \\
\hline $15-24$ & 1.0 & 1.0 & 1.0 \\
\hline $25-34$ & $1.81(1.16,2.84)^{* *}$ & $0.48(0.16,1.49)$ & $0.68(0.11,4.27)$ \\
\hline $35-44$ & $2.43(1.56,3.77)^{* *}$ & $1.51(0.74,6.62)$ & $0.89(0.24,3.27)$ \\
\hline $45-54$ & $1.46(0.84,2.53)$ & $1.38(0.62,1.96)$ & $0.32(0.08,1.26)$ \\
\hline $55-64$ & $1.26(0.42,3.79)$ & $1.30(0.79,1.95)$ & $0.82(0.21,3.15)$ \\
\hline$>65$ & $0.69(0.25,1.94)$ & $2.59(1.07,2.11)^{*}$ & $1.38(0.35,5.49)$ \\
\hline \multicolumn{4}{|l|}{ Victims' education } \\
\hline College/university & 1.0 & 1.0 & 1,0 \\
\hline Secondary & $0.92(0.57,1.46)$ & $0.99(0.67,1.68)$ & $1.06(0.55,2.45)$ \\
\hline Primary & $1.39(0.81,2.36)$ & $1.18(0.69,2.04)$ & $1.64(0.72,3.74)$ \\
\hline \multicolumn{4}{|l|}{ Partners' education } \\
\hline College/university & 1.0 & 1.0 & 1,0 \\
\hline Secondary & $0.97(0.59,1.59)$ & $0.80(0.49,1.29)$ & $0.79(0.35,1.77)$ \\
\hline Primary & $1.15(0.69,1.91)$ & $1.09(0.44,1.22)$ & $1.02(0.45,2.32)$ \\
\hline \multicolumn{4}{|l|}{ Marital status } \\
\hline Not married & 1.0 & 1.0 & 1,0 \\
\hline Living with men without official marriage & $0.44(0.20,0.94)$ & $0.62(0.30,1.28)$ & $0.69(0.24,2.23)$ \\
\hline Divorced & $1.82(0.67,2.68)$ & $0.65(0.32,1.31)$ & $1.94(0.78,4.81)$ \\
\hline Officially married & $2.18(1.13,4.43)^{*}$ & $1.89(1.09,3.47)^{*}$ & $1.35(0.82,3.51)$ \\
\hline \multicolumn{4}{|l|}{ Employment status of victim } \\
\hline Employed & 1.0 & 1.0 & 1.0 \\
\hline Unemployed & $1.31(0.86,1.49)$ & $1.37(1.05,1.80)^{*}$ & $0.64(0.39,1.13)$ \\
\hline \multicolumn{4}{|l|}{ Employment status of partner } \\
\hline Employed & 1.0 & 1.0 & 1.0 \\
\hline Unemployed & $1.63(1.03,2.64)^{*}$ & $1.95(1.19,3.51)^{*}$ & $1.13(1.06,2.90)^{*}$ \\
\hline \multicolumn{4}{|c|}{ Household monthly income (by thousand, local currency) } \\
\hline$>240$ & 1.0 & 1.0 & 1.0 \\
\hline $120-239$ & $2.26(1.45,9.11)^{*}$ & $2.01(1.68,4.55)^{* *}$ & $1.93(1.02,4.74)^{*}$ \\
\hline$<119$ & $2.82(1.49,7.70)^{*}$ & $2.97(1.55,9.99)^{* *}$ & $2.01(1.11,5.95)^{*}$ \\
\hline \multicolumn{4}{|l|}{ Housing } \\
\hline In own private ger/apartment & 1.0 & 1.0 & 1.0 \\
\hline With parents/parents in-laws/children & $1.31(0.36,4.76)$ & $0.83(0.51,1.37)$ & $2.49(1.25,4.99)$ \\
\hline Rented house/ger/a room & $1.91(1.02,4.56)^{*}$ & $2.71(1.21,5.56)^{*}$ & $2.39(1.18,3.37)^{* *}$ \\
\hline In care houses provided by overnment & $0.88(0.22,3.49)$ & $0.60(0.34,1.07)$ & $0.42(0.12,0.98)$ \\
\hline \multicolumn{4}{|l|}{ Partner use alcohol } \\
\hline No & 1.0 & 1.0 & 1.0 \\
\hline Yes & $16.70(11.42,24.42)^{* *}$ & $15.87(10.98,22.94)^{* *}$ & $3.32(1.88,5.85)^{* *}$ \\
\hline
\end{tabular}

${ }^{*} p<0.05 ;{ }^{* *} p<0.01$.

Alcohol is associated with all three types of violent events after controlling for other risk factors (Table 2). A partner with a heavy drinking habit usually puts a woman at greater risk for violence. ${ }^{26,27}$ In our study, the ORs of physical and emotional violence by an alcoholic partner were above 15.9-16.7, which is similar to that reported in a study conducted in the United States. ${ }^{28}$ People with lower incomes and those who are unemployed are also associated with an increased risk for the three types of domestic violence. From our field observations, alcohol abuse is frequently associated with poverty and unemployment. These three factors linked together produce a high risk of IPV and unhappy marriage and contribute to the growth of female-headed households and homeless children in Ulaanbaatar. In fact, the protection shelter operated by the National Center against Violence in Ulaanbaatar has accommodated increasing numbers of runaway children in recent years, many of whom were likely fleeing violence in the home. ${ }^{2,30}$

This study indicates the need for educating Mongolian people on conflict management skills, especially among men, who are the main perpetrators. In addition, they must also be taught about the consequences of such violence on their children, including the negative impact on cognitive, mental, and physical development. ${ }^{31,32}$ Some educational programs have been reported to be effective in changing men's discriminatory and controlling attitudes toward women in western countries, ${ }^{33}$ and such program should be considered in Mongolia in the future.

Efforts to prevent and treat problem drinking among young men would likely help to reduce IPV. ${ }^{34}$ In the United States, for example, rates of IPV violence have been reported to decrease by $15 \%$ subsequent to alcoholism treatment. ${ }^{35}$ This study also suggests increasing employment for men may help reduce poverty and alcohol abuse and, thus, domestic violence. In fact, a pilot project organized by the Mongolian Women Farmers' Association to increase household income showed a positive effect on reducing household tension, alcohol abuse, and violence by an intimate partner. ${ }^{36}$

Another major reason for widespread violence may be related to the lack of accessibility to legal information in Mongolia and the inadequate efforts of governmental 
organizations in disseminating information about enforcement of existing laws. We recommend that both governmental and nongovernmental agencies provide more financial and technical support to the National Centre against Violence, the main institution in Mongolia devoted to reducing domestic violence, in order to establish more safety shelters at provincial and district levels to help the victims of violence. Through providing more multidimensional client services, including crisis intervention, temporary housing, medical aid, clinical counseling programs, legal services, and such community outreach services $^{32}$ as support groups or networks, the National Centre against Violence can assist and empower women and help build attitudes that no longer condone violence of any kind against women. For example, a free phone system with 24-hour help and police emergency service has been provided to all Mongolian people for immediate access, ${ }^{33}$ but women and children must be educated and trained to use it whenever they are faced with or threatened by IPV. Thus, there is a need for constructing a more flexible and multisectoral system of cooperation among agencies and communities in Mongolia so that domestic violence can be eliminated and its victims treated and protected.

\section{Conclusions}

Domestic violence against women is widespread in Mongolia. Violence against women is usually committed in family circles and is often away from public view. All three types of violence we examined in this study (physical, emotional, economic) were associated with having an alcohol-abusing partner, having a low income, and being unemployed. Being less educated, elderly, a divorced woman, and living in a rented or shared house were associated with an increased risk of emotional violence. For prevention measures to be effective, it appears that all these factors should be considered together. Because of the evidence provided in this study, there was a great lobby in the Mongolian parliament to establish a special law for early prevention, recognition, and control of domestic violence, which was successfully enacted in 2005. More studies are needed to determine the health effects or consequences of the levels of domestic violence we have documented here.

\section{Acknowledgments}

Special thanks go to cooperators and collaborators of the UNICEF Mongolia and B. Darykhand, Project Officer for Child Protection, for financial support; the Family Group Practitioners of Health Centers of Bayanzurkh and Songinokharkhan districts; the researchers of the Human Resource Development Department of the Directorate of Medical Services; Ms. Badamtsetseg, Officer of the National Center Against Violence; B. Enkhtsetseg, Officer of Child Right Centre for management of this study and for interviewing subjects. We are indebted to Ms. Chao-Wan Huang, CPH of National Taiwan University, for editorial assistance.

This study was supported by the Project for Child Protection of the UNICEF-Mongolia. The content of this article does not represent the official views of the funding agencies.

\section{Disclosure Statement}

No competing financial interests exist.

\section{References}

1. World Health Organization. Urban violence and health. Determinants and management. Kobe: Kobe Centre, 2001:101-135.

2. World Health Organization. Violence and health. Proceedings of a WHO global symposium. Kobe: Kobe Centre, 2000:155-199.

3. Asian Forum of Parliamentarians on Population and Development and United Nations Population Fund. Proceedings of Inter-Country workshop on parliamentary advocacy for the elimination of violence against women in East and South-East Asia and the Pacific; 2001 June 19-21; Bangkok, Thailand. Bangkok: Asian Forum of Parliamentarians on Population and Development, 2001:3-16.

4. Women Lawyers' Association and National Center against Violence. Ways for prevention of domestic violence: Domestic violence handbook for Mongolia and Central Asia. Ulaanbaatar, Mongolia: Inter Press; 2003. p. 259-261.

5. Ministry of Health in Mongolia and United Nations Population Fund. National Program on Reproductive Health. Ulaanbaatar, Mongolia: Admon Printing Company; 2002. p. 4-9.

6. Ministry of Health in Mongolia. State policy on public health. Ulaanbaatar, Mongolia: Munkhün Useg Press; 2002. p. 5-15.

7. Ministry of Health in Mongolia. Legislative acts on Family Development. Ulaanbaatar, Mongolia: Eruul Enkh Printing company; 2004. p. 10-15.

8. United Nations Children's Fund. Situation of children in difficult circumstances. Ulaanbaatar, Mongolia: Admon Printing Company; 1998. p. 5-41.

9. Ministry of Health in Mongolia. Reference book for public health legislation. Ulaanbaatar: Eruul Enkh Publisher, 2003:15-31, 45-51.

10. Ministry of Law and Internal Affair. Criminal code and criminal procedure law of Mongolia. Ulaanbaatar, 2002:3-13.

11. National Centre Against Violence. Improving psychological strengths of women fighting against violence. Ulaanbaatar, Mongolia: Inter Press; 1999. p. 9-25.

12. National Centre Against Violence. Violence within the family [Fact sheet]. Ulaanbaatar, Mongolia: Inter Press; 2002. p. 5-7.

13. National Statistical Office. Population and housing census2000: Report of the National Population Census. Ulaanbaatar, Mongolia: Admon Printing Company; c2001 Dec. Report No: MNG-NSO-MN-PHC-2000-v2.0. p. 10-33. Mongolian.

14. International Fund for Agricultural Development. Rural poverty in Mongolia. Rural Poverty portal. Available at 66.218.69.11/search/cache?ei=UTF-8\&p=women+headed + family + in + mongolia\&fr $=$ slv8-msgrv\&u $=$ www.ruralpoverty portal.org/english/regions/asia/mng/index.htm\&w=women+ woman +headed +head +heads +family +families + mongolia $\& \mathrm{~d}=$ VLqZ10fiRyCH\&icp $=1 \& . i n t \mathrm{l}=$ us Accessed November 2008.

15. Krug EG, Dahlberg LL, Mercy JA, Zwi AB, Lozano R, eds. WHO world report on violence and health, 2002. Available at www.who.int/violence_injury_prevention/violence/world_ report/en/full_en.pdf Accessed July 2008.

16. International Labor Office and World Health Organization. Framework guidelines for addressing workplace violence in the health sector, 2002. Available at whqlibdoc.who.int/ publications/9221134466.pdf Accessed July 2008.

17. National Statistical Office of Mongolia. Living standard, 2008. Available at www.nso.mn/v1/index.php Accessed December 2008. 
18. Garcia-Moreno C, Jansen HAFM, Ellsberg M, Heise L, Watts C. WHO multi-country study on women health and domestic violence against women: Initial results on prevalence, health outcomes and women responses. Geneva: World Health Organization, 2005. Available at whqlibdoc.who. int/publications/2005/9241593512_eng.pdf Accessed November 2008.

19. Watts C, Zimmerman C. Violence against women: Global scope and magnitude. Lancet 2002;359:1232-1237.

20. Hindin MJ, Adair LS. Who's at risk? Factors associated with intimate partner violence in the Philippines. Soc Sci Med 2002;55:1385-1399.

21. Lown A, Vega W. Prevalence and predictors of physical partner abuse among Mexican American women. Am J Public Health 2001;91:441-445.

22. White HR, Chen PH. Problem drinking and intimate partner violence. J Stud Alcohol 2002;63:205-214.

23. Cunradi CB, Caetano R, Schafer J. Alcohol-related problems, drug use, and male intimate partner violence severity among U.S. couples. Alcohol Clin Exp Res 2002;26:493-500.

24. Hyman I, Forte T, Mont JD, Romans S, Cohen MM. The association between length of stay in Canada and intimate partner violence among immigrant women. Am J Public Health 1996;4:654-659.

25. Neff JA, Holamon B, Schluter TD. Spousal violence among Anglos, blacks and Mexican Americans: Role of demographic variables, psychological predictors, and alcohol consumption. J Fam Violence 1995;10:1-21.

26. Fals-Stewart W. The occurrence of partner physical aggression on days of alcohol consumption: A longitudinal diary study. J Consult Clin Psychol 2003;71:41-52.

27. Jewkes R. Intimate partner violence: Causes and prevention. Lancet 2002;359;1423-1429.

28. Surjadi C. Violence prevention and health development: Experiences from Indonesian cities. Violence and health. Proceedings of a WHO global symposium, Japan. 2000:257-267.
29. National Centre for Child Right. Situation of child's right in Mongolia. Ulaanbaatar: ADMON Publisher, 1995:6-9.

30. United Nations Development Programs. Mongolian human development report Ulaanbaatar: ADMON Publisher, 2003: 12-29.

31. Romans SE, Poore MR, Martin JL. The perpetrators of domestic violence. Med J Australia 2000;173:484-488.

32. Perry BD, Azad I. Posttraumatic stress disorders in children and adolescents. Curr Opin Pediatr 1999;11:310-316.

33. Robertson N. Stopping family violence programmes: Enhancing the safety of battered women or producing better educated batterers? NZ J Psychol 1999;28:68-78.

34. Lipsky S, Caetano R, Field CA, Bazargan S. The role of alcohol use and depression in intimate partner violence among black and Hispanic patients in an urban emergency department. Am J Drug Alcohol Abuse 2005;31:225-242.

35. O'Farrell TJ, Fals-Stewart W, Murphy M, Murphy CM. Partner violence before and after individually based alcoholism treatment for male alcoholic patients. J Consult Clin Psychol 2003;71:92-102.

36. The Asian Foundation. The Mongolian Women Farmers' Association. Monitoring and evaluation research report, 2006. Available at www.asiafoundation.org/resources/pdfs/ MGMWFAresearcheng.pdf Accessed November 2008.

Address correspondence to: Jung-Der Wang, M.D., Sc.D. Institute of Occupational Medicine and Industrial Hygiene National Taiwan University College of Public Health No. 17 Xu-Zhou Road Taipei 100 Taiwan

E-mail: jdwang@ntu.edu.tw 